\title{
Molecular Plasticity of Adult Bergmann Fibers Is Associated with Radial Migration of Grafted Purkinje Cells
}

\author{
Constantino Sotelo, ${ }^{1}$ Rosa-Magda Alvarado-Mallart, ${ }^{1}$ Monique Frain, ${ }^{2}$ and Muriel Vernet $^{3}$ \\ 'Neuromorphologie: Développement, Evolution, INSERM U. 106, Hôpital de la Salpétrière, 75651 Paris Cedex 13, France, \\ 'Biologie Moléculaire du Développement, INSERM U. 368 Ecole Normale Supérieure, 75230 Paris Cedex, France, and \\ ${ }^{3}$ Institut Cochin de Génétique Moléculaire, CJF 9003 INSERM, 75014 Paris, France
}

\begin{abstract}
Embryonic Purkinje cells (PCs) from cerebellar primordia grafted in adult pcd mutant cerebellum replace missing PCs of the host, and become synaptically integrated into the defective cerebellar circuit. This process of neuronal replacement starts with the invasion of grafted PCs into the host cerebellum, and their radial migration through its molecular layer. The present study is aimed at determining whether the glial axes for this migration are embryonic radial glial cells that comigrate with the grafted PCs, or adult Bergmann fibers of the host, transiently reexpressing the molecular cues needed for their guidance of the migration. Transplants from a transgenic mouse line (Krox-20/lacZ14) in which Bergmann fibers could be identified by lac $Z$ expression reveal that, despite the presence of X-gal-stained Bergmann fibers in the graft remnants and of grafted PCs in the host molecular layer, all Bergmann fibers in the host cerebellum lack of $\beta$-galactosidase activity. Thus, these migratory axes belong to the host, not to the donor. Transplants from normal isogenic mouse embryos show that during the radial migration of grafted PCs (7 d after grafting) the involved host Bergmann fibers reexpress nestin (identified with monoclonal antibody Rat-401 immunostaining), normally expressed only by immature Bergmann fibers. Five days later, when grafted PCs have arrested their migration, host Bergmann fibers again become Rat-401 negative. These results indicate that embryonic PCs can trigger in adult cerebellum the molecular changes necessary for their own migration and ultimate synaptic integration in the host cortical circuitry.

[Key words: Purkinje cell migration, embryonic and adult neural cell interactions, cerebellar grafting, nestin expression in adult Bergmann fibers, molecular plasticity, glial axes for neuronal migration]
\end{abstract}

Neurons in adult mouse cerebellum do not proliferate. In consequence, degenerating neurons cannot be replaced by a selfrepair process. Embryonic neurons, however, can be grafted into

\footnotetext{
Received Mar. 22, 1993; revised July 1, 1993; accepted July 13, 1993.

We are indebted to Dr. Susan Hockfield for the gift of the mAb Rat-401, and for communicating unpublished results, as well as to Dr. L. E. M. Lawson for the gift of the anti-CaBP antibody. We are also grateful to Dr. Merle Ruberg for careful reading of the manuscript and important improvements. Sincere thanks to Dr. Jean-Louis Guénet for breeding the mutant mice, to Ms. Rosine Werhlé for her help with the transgenic mouse line, to Ms. Beatrice Cholley for her help with immunocytochemical techniques, to Mr. Denis Le Cren for photographic assistance, and to Mrs. Anne-Marie Skévis for typing the manuscript.

Correspondence should be addressed to Dr. Constantino Sotelo, INSERM U-106, Hópital de la Salpétrière, 47 Boulevard de l'Hópital, 75651 Paris Cedex 13, France. Copyright (c) 1994 Society for Neuroscience $0270-6474 / 94 / 140124-10 \$ 05.00 / 0$
}

adult cerebellum and become functionally integrated into the synaptic circuitry of the cerebellar cortex of the host (Sotelo and Alvarado-Mallart, 1991). The cerebellar mutant mouse strains $p c d, n r$, and $L c$, in which Purkinje cells (PCs) die (Sidman and Green, 1970; Mullen et al., 1976; Caddy and Biscoe, 1979; Wassef et al., 1987; Dumesnil-Bousez and Sotelo, 1992), have provided models for studying graft integration (Sotelo and Alvarado-Mallart, 1986, 1987a, 1991, 1992; Dumesnil-Bousez and Sotelo, 1993). Penetration of grafted PCs into the cerehellum of mutant hosts begins 3-4 d after grafting (DAG 3-4) by tangential migration at the surface of the folia adjacent to the graft, followed by radial migration into the folia along Bergmann glial fibers (DAG 5-8). By DAG 10 all leading processes of PCs have arrived at the border of the host molecular and granule layer, provoking a stop signal for the migration (Sotelo and AlvaradoMallart, 1987b; Sotelo et al., 1990).

The timing and the nature of the cellular interactions involved in the migration of grafted PCs into the host cerebellum are similar to those that take place during normal ontogeny, suggesting that, in both cases, the developmental program is regulated autonomously by the participating cells, independent of external factors, as by an internal clock (Sotelo and AlvaradoMallart, 1987b; Sotelo et al., 1990). Nlthough little is known about the molecular identity of the signals involved, it is clear that they are developmentally regulated and transiently expressed. During ontogenesis, it might be thought that expression of the necessary signals by the participating cells is coordinated because the cells involved are similar in age. This would not be the case, however, when embryonic neurons are grafted into adult brain. This raises the question as to whether the grafted embryonic PCs induce adult host cells, in particular the Bergmann glia, to transiently reexpress the molecular signals needed for their migration and synaptic integration into the host (Sotelo and Alvarado-Mallart, 1987b), or whether isochronic embryonic astrocytes, which express the appropriate factors because of their age, also migrate from the graft, acquire the Bergmann phenotype, and provide the substrate for migration of the PCs.

In order to determine whether comigration of embryonic PCs and astrocytes, or "rejuvenation" of host glia by the embryonic PCs is involved in graft integration, the following experiment was performed. Adult $p c d$ mutant mice, in which PCs die between postnatal days 17 and 45 (Mullen et al., 1976), were grafted with cerebellar primordia from homozygous embryos of a transgenic mouse line, Krox-20/lacZ14, which shows an ectopic expression pattern of the hybrid Krox-20/lacZ gene (M. Frain, P. Charnay, R. Werhle, and C. Sotelo, unpublished observations). In transgenic animals, $\beta$-galactosidase activity is 
detected in the cerebellum, exclusively in Golgi epithelial cells and their Bergmann fibers. Matured Bergmann fibers originating from the transgenic graft could, therefore, be distinguished from Bergmann fibers of the $p c d$ host.

In order to determine whether, during the migration of grafted PCs, Bergmann fibers of the adult host express antigens corresponding to an earlier developmental stage, sections of cerebella that had received transplants from isogenic mouse embryos were immunostained during tangential migration (DAG 5), during radial migration on the Bergmann fibers (DAG 7), and after migration is completed (DAG 13), with the monoclonal antibody (mAb) Rat-401. This antibody recognizes nestin, an antigen expressed in proliferating cells during neurogenesis (Lendahl et al., 1990), and also transiently stains the glial axes guiding neuronal migration in the developing CNS of the rat (Hockfield and McKay, 1985).

We report (1) that transplanted cells expressing the lac $Z$ gene do not migrate from the graft to the host molecular layer, and (2) that there is a close spatiotemporal correlation between expression of the Rat-401 antigen by host Bergmann glial fibers and radial migration of grafted PCs. It is concluded that grafted embryonic PC's induce, in the cerebellum of adult PC-deficient mice, transient expression of signals associated with their migration that recapitulatc mcchanisms cmployed in normal ontogenesis.

\section{Materials and Methods}

Mutant mice. The $p c d$ mutant mice were obtained primarily from the Jackson Laboratory (Bar Harbor, ME) and raised at the Pasteur Institute (Unité Génétique des Mammifères, Paris). Homozygous $p c d / p c d$ were obtained by intercrossing heterozygous mice.

Hybrid gene construction and generation of transgenic mice. Two BgllI fragments of 7 and 7.2 kilobases $(\mathrm{kb})$, respectively, were recovered from the $16 / 13$ cosmid (Chavrier et al. 1989) containing the mouse Krox-20 gene and cloned into the BamHI site of pBluescript $\mathrm{KS}$ to reconstruct the Krox-20 gene. A 3 kb BamHI fragment from plasmid pMC1871 (Pharmacia), containing the Fscherichia coli lac7 gene deleted of the first eight codons, was then introduced into the unique internal BglII site to generate a Krox-20/lacZ fusion gene. For egg microinjection, an $11 \mathrm{~kb}$ SacII-SpeI fragment, which includes the Krox-20/lacZ hybrid gene, $\sim 2 \mathrm{~kb}$ of $5^{\prime}$ flanking sequences, and $\sim 1 \mathrm{~kb}$ of $3^{\prime}$ flanking sequences, was excised. Linear DNA was isolated by electrophoresis on agarose gel, purified on Elutip D (Schleicher and Schüll), and injected into zygotes of B6D2 F1 females mated to identical males. Production of transgenic mice was carried out as described by Hogan et al. (1986). Transgenic mice carrying the Krox-20/lacZ hybrid gene were identified by tail DNA analysis and bred to B6D F1 males to establish transgenic lines. Expression of the transgene was analyzed by staining the embryos for $\beta$-galactosidase activity (Sanes et al. 1986).

Transplantation into adult pcd cerebellum. Donor tissue was obtained from the cerebellar primordia of 12 d (E12) Krox-20/lacZ14 homozygous transgenic embryos or C57BL/6J embryos (mating day was considered $\mathrm{E} 0$ ). The embryos were removed individually from the mother under chloral hydrate anesthesia $(300 \mathrm{mg} / \mathrm{kg}$ body weight) and placed into phosphate-buffered saline ( $\mathrm{pH} 7.2)$ with glucose $(6 \mathrm{mg} / \mathrm{ml})$, for the duration of the grafting procedure. Overlying tissue layers and pia were removed and the cerebellar primordia were dissected out, with microdissecting tweezers under an operating microscope. Only central portions of the metencephalic alar plates were used for transplantation to avoid grafting noncerebellar neuroepithelium. The tissue was cut into small blocks of about $0.5-1 \mathrm{~mm}$ diameter, which served as solid grafts. Hosts were homozygous $p c d$ mutant mice of the $\mathrm{C} 57 \mathrm{BL} / \mathrm{cdj}$ strain, aged 2-6 months. They were anesthetized with chloral hydrate, and immobilized in a David Kopf stereotaxic frame adapted for small rodents. Aftcr craniotomy of the occipital bonc, the dorsal surfacc of the postcrior vermal lobe was exposed. Individual pieces of the selected embryonic cerebellar tissue were drawn into a glass cannula connected by a plastic tube to a $10 \mu \mathrm{l}$ Hamilton syringe. The tip of the micropipette was inserted by hand in a posteroanterior direction, and the graft was deposited at variable depths within the host cerebellar parenchyma. After grafting, the skin was closed, and the mouse was warmed and returned to its cage. Mice were housed two or three to a cage with free access to food and water, and a $12 \mathrm{hr}: 12 \mathrm{hr}$ day/night schedule. Mutant mice implanted with Krox-20/lacZ14 primordia survived for 1-2 months; those implanted with isogenic embryos survived 5,7 , and $13 \mathrm{~d}$.

Perfusion. Mice carrying the Krox-20/lacZ14 transgene (transgenic mice, and $p c d$ mice transplanted with donor tissue from transgenic embryos) were fixed intracardially, under ether anesthesia, with a solution of $2 \%$ paraformaldehyde, $0.1 \%$ glutaraldehyde in $0.12 \mathrm{M}$ phosphate buffer ( $\mathrm{pH} \mathrm{7.2)}$ for $20 \mathrm{~min}$. After dissection, the brains were postfixed by immersion in the same fixative for $4 \mathrm{hr}$. The 1-d-old (P1) and P8 mouse pups resulting from the breeding of heterozygous $p c d$ mice, as well as those transplanted with E12 C57BL cerebellar tissue, were perfused with a solution of $4 \%$ paraformaldehyde in the phosphate buffer for over $30 \mathrm{~min}$. The dissected brains were postfixed in the same fixative by overnight immersion at $4^{\circ} \mathrm{C}$. Blocks containing the cerebellum and attached brainstem of all fixcd micc werc prepared and infiltrated for $2 \mathrm{~d}$ in $30 \%$ sucrose.

$\beta$-Galactosidase detection. The appropriate cerebella were cut on a freezing microtome at $26 \mu \mathrm{m}$ in either the sagittal or the frontal plane. $\beta$-Galactosidase activity was detected by incubating free-floating sections in a solution containing $2 \mathrm{~mm} \mathrm{MgCl}_{2}, 4 \mathrm{~mm} \mathrm{~K} 3 \mathrm{Fe}(\mathrm{CN})_{6}, 4 \mathrm{~mm}$ $\mathrm{K}_{4} \mathrm{Fe}(\mathrm{CN})_{6}$, and $4 \mathrm{mg} \cdot \mathrm{ml}^{-1}$ of 5 -bromo-4-chloro-3-indoyl- $\beta$-D-galactopyranoside (X-gal; Bethesda Research Labs Life Technologies). The incubation was carried out at $37^{\circ} \mathrm{C}$ for $4 \mathrm{hr}$. After $\beta$-galactosidase detection, the sections were either double labeled with an anti-calbindin $(\mathrm{CaBP})$ antibody or counterstained with neutral red.

Antibodies. The polyclonal anti-CaRP antiserum, obtained in rabbit against chick CaBP (Spencer et al., 1976), was kindly supplied by Dr. D. E. M. Lawson (Section of Neuroanatomy, Yale University). Rat-401 is a mouse monoclonal antibody (mAb) obtained from fixed spinal cord of E15 rat embryos (Hockfield and McKay, 1985), which recognizes nestin (Lendahl et al., 1990). The mAb Rat-401 was generously provided by Dr. Susan Hockfield (Institute of Animal Physiology and Genetics Research, New Haven, CT). These antibodies were used at dilutions of $1: 8000$ to $1: 10,000$ for anti-CaBP and $1: 500$ of the full-strength supernatant for mAb Rat-401.

Immunocytochemistry. For the cellular analysis of the Krox-20/lacZ14 cerebellum, the X-gal-stained sections were incubated overnight at room temperature with the polyclonal rabbit anti-CaBP antiserum, and processed according to the peroxidase-antiperoxidase (PAP) method of Sternberger et al. (1970). For study of the $p c d$ cerebella grafted with the E12 transgenic cerebellar primordium, after the histochemical detection of $\beta$-galactosidase activity, the sections were also treated with the antiCaBP antiserum. CaBP immunoreactivity was revealed in alternate sections either by the PAP method or by the immunofluorescence. The study of Rat-401 expression in postnatal and lesioned $p c d$ cerebella was performed in free-floating frozen sections immunoprocessed with the mAb Rat-401 and revealed by the PAP method. Finally, the correlation between radial migration of grafted PCs and reexpression of glial Rat401 antigen was analyzed in double-labeled sections. They were incubated overnight at room temperature with the mAb Rat-401 and the polyclonal rabbit anti-CaBP antibody. Rat-401 was revealed with the PAP method (Sternberger et al., 1970) and, thereafter, CaBP-immunoreactivity was visualized with a goat anti-mouse antibody conjugated to fluorescein isothiocyanate. Sections in which the incubation with primary antibodies was omitted were used as controls.

\section{Results}

\section{Validation of the markers}

$\beta$-Galactosidase activity identifies epithelial cells and Bergmann fibers from transgenic graft donors. Transgenic mouse lines carrying the Krox-20/lacZ hybrid gene have been generated. In one particular line, number 14 , the hybrid gene is fully expressed in the CNS at P22. The gene product, as revealed by X-gal staining, is most abundant in the cerebellum, where it is present throughout all vermian (Fig. $1 A$ ) and hemispheric cortices, but only in the molecular layer. The staining covers the entire molecular layer (Fig. $1 A, B$ ), but is most intense at the interface between the molecular and granule cell layers, which appears as a fine scalloped band composed of alternating, irregular intensely pos- 

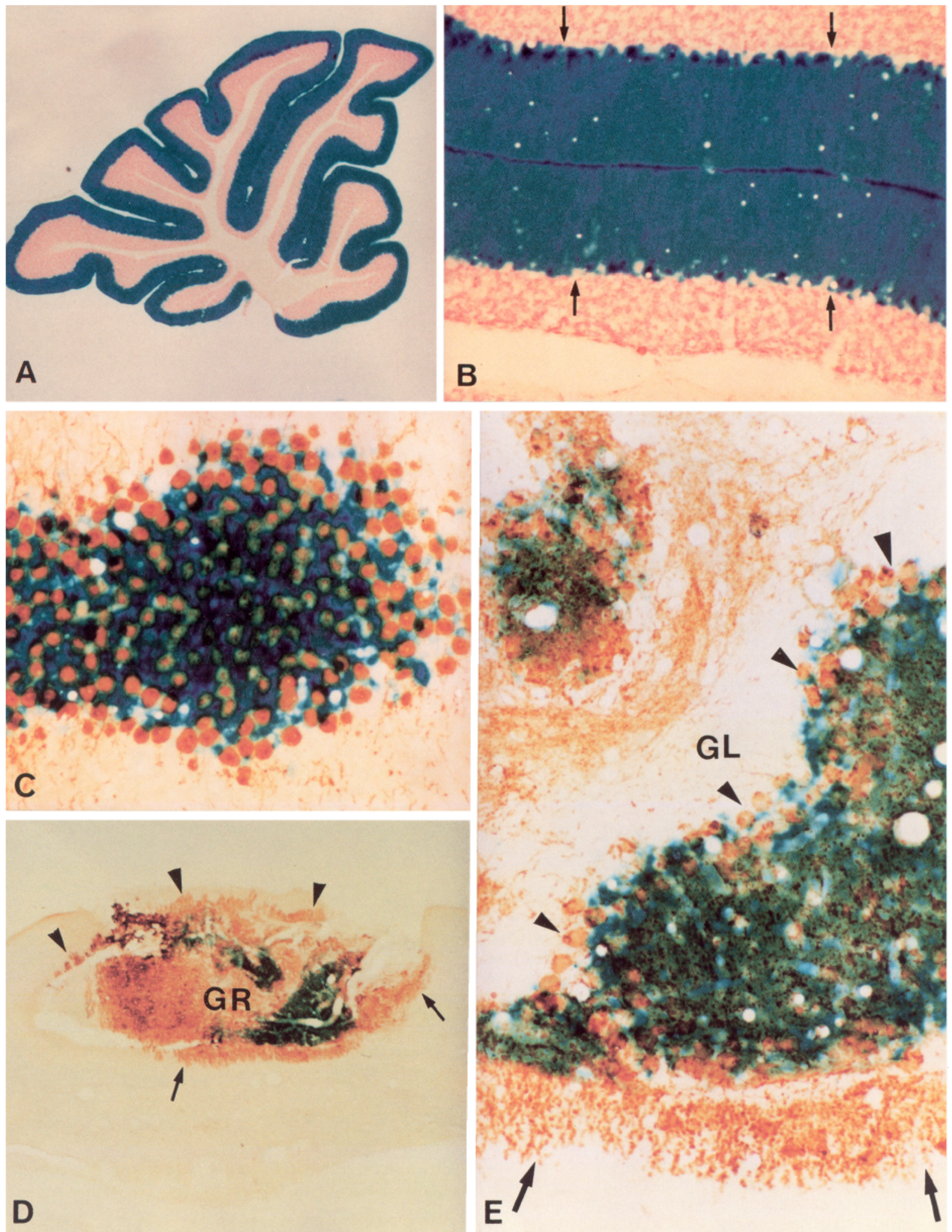

Figure 1. Expression of the Krox-20/lacZ transgene in P22 cerebellum of the transgenic mouse line ( $A-C)$, and 1 month after transplantation into adult $p c d$ cerebellum $(D, E)$. $A$, Blue X-gal-positive reaction is present all over the molecular layer of this midsagittal section, from lobule I to X. $B$, At higher magnification, the striate appearance of the blue staining is noticeable. Moreover, at the interface between molecular and granular layers, the blue reaction is stronger and exhibits a scalloped appearance (arrows). The section was lightly stained with neutral red to better reveal the cytoarchitectonic of the cerebellum. $C$, Double labeling with X-gal and $\mathrm{CaBP}$ of a transgenic mouse cerebellum cut in the frontal plane. The disposition of the cellular elements with blue, X-gal-positive reaction, surrounding the PC bodies-visualized by their CaBP immunoreactivitypermits their identification as Golgi epithelial cells. $D$, Double labeling, X-gal and CaBP, of a frontal section of a pcd cerebellum containing a large graft remnant $(G R)$ in lobule VI, and numerous grafted PCs within the molecular layer of host lobules VI (arrowheads) and VIII (arrows). E, Higher magnification of the same graft as in $D$ illustrating the presence of lacZ-expressing cells (blue reaction) in the molecular layer of two folia of the 


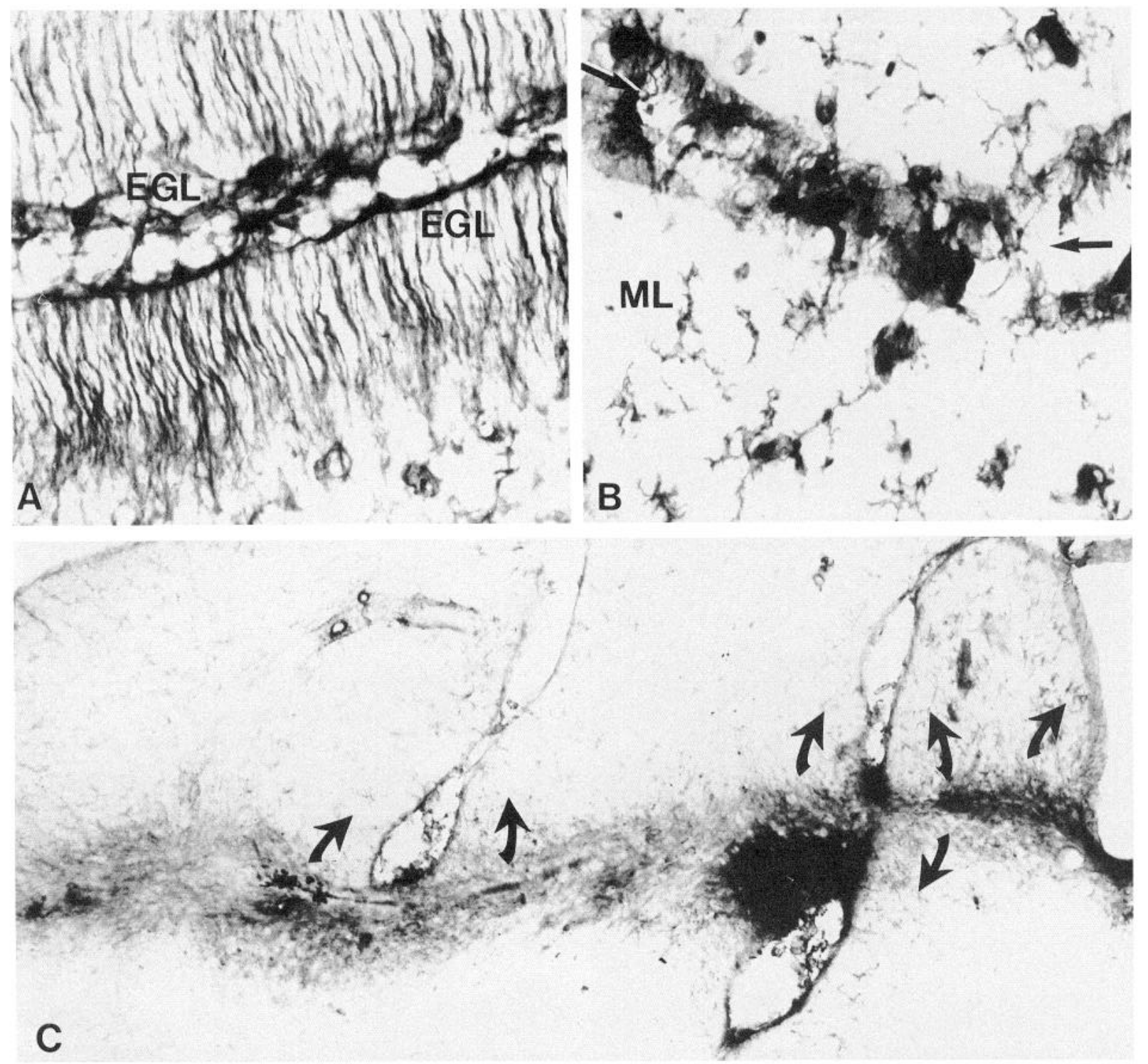

Figure 2. Expression of Rat-401 antigen in postnatal, adult normal, and adult postlesioned $p c d$ cerebellum. $A$, At P8, the mAb Rat-401 immunostains Bergmann fibers forming the characteristic palisades in the developing molecular layer. Note the lack of immunoreactive cells, other than Bergmann fibers, in the external granular layer $(E G L)$. B, Four-month-old $p c d$ cerebellum. The immunostaining identifies numerous cellular profiles exhibiting typical features of microglial cells, and dispersed throughout the molecular layer $(M L)$. The arrows point to the interfolial surface. $C$, Three-month-old $p c d$ cerebellum, $7 \mathrm{~d}$ after its posteroanterior perforation with the glass micropipette used for transplantation. Rat-401 reexpression occurs all along the cannula track in reactive astrocytes. The arrows point to molecular layer regions intercrossed by the lesion in which Bergmann fibers lack immunostaining, and the only reactive elements are microglial cells. Magnification: $A, 340 \times ; B, 275 \times ; C, 130 \times$.

itive and negative spots (Fig. 1B). Within the molecular layer, fine fibers, passing vertically through the cortex to the subpial surface, stand out against the blue background, giving this layer a radially striated appearance (Fig. $1 B$ ). On frontal sections passing tangentially through the PC layer (Fig. 1C), PC somata, identified by $\mathrm{CaBP}$ immunohistochemistry, occupy the unstained holes in the intensely blue sieve-like band at the molecular/granule cell layer interface. The only cellular elements in the cerebellum that correspond to those expressing $\beta$-galactosidase activity are the Golgi epithelial cells and their Berg- mann fibers. This pattern of expression of the transgene in mouse line 14 likely results from its particular site of integration since it was not observed with the other lines (data not shown) and it does not correspond to the normal Krox-20 expression pattern (P. Topilko, S. Schneider-Maunoury, G. Levi, C. Babinet, and P. Charnay, unpublished observations).

mAb Rat-401 permits identification of migration-related Bergmann fibers in pcd mutant mice. In order to determine whether the $p c d$ mutation affects postnatal expression of nestin, cerebella from the progeny of heterozygous mutant mice were immu-

graft remnant. The arrowheads point to grafted PC bodies in the graft remnant separating the molecular from the granular cell layer $(G L)$. Note the lack of $\beta$-galactosidase reactivity in the host molecular layer containing grafted PCs (arrows). Magnification: $A, 20 \times ; B, 135 \times ; C, 150 \times ; D$, $19 \times ; E, 190 \times$. 

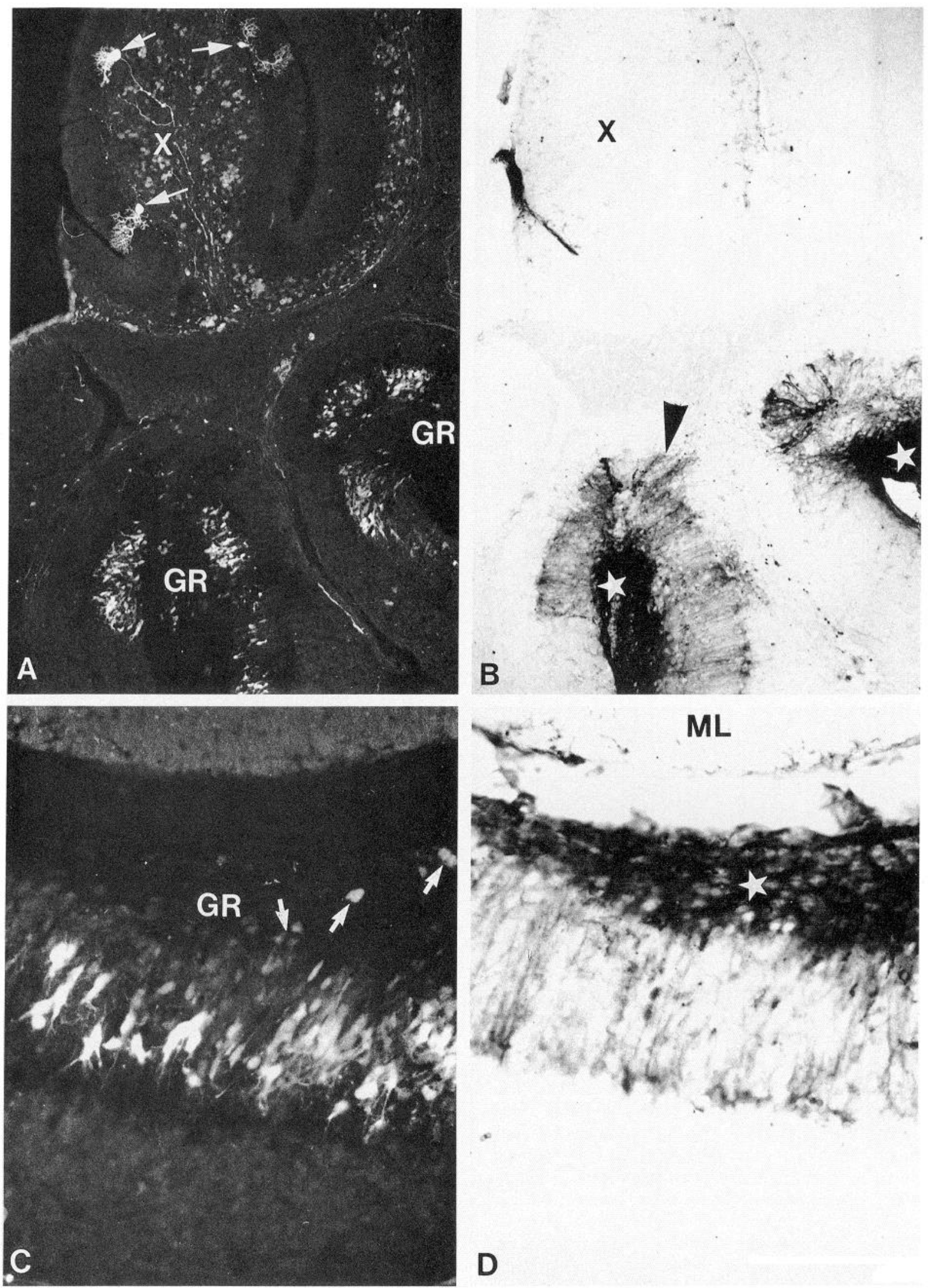

Figure 3. Rat-401 antigen expression in Bergmann fibers of adult $p c d$ mice at 7 DAG. The mutant cerebella were sectioned sagittally, and double labeled with mAb Rat-401 and anti-CaBP antisera. $A$ and $B$, Low magnification of the same section (CaBP staining in $A$ and Rat-401 in $B$ ). In lobule $\mathrm{X}(X)$ three $p c d$ PCs remain (arrows), without preservation of Rat-401 in adjacent Bergmann fibers. The graft remnants $(G R)$, located in the anterior lobe, exhibit an intense Rat-401 immunoreactivity (stars). Note the spatial correlation between the radial migration of CaBP-positive PCs 
nostained with mAb Rat-401 at P1 and P8, one litter at each time period. This procedure was necessary since the clinical $p c d$ phenotype can be detected only after the second postnatal week, whereas granule cell migration along Bergmann fibers begins at birth and peaks at P8. Normal, heterozygous or homozygous pups could not be distinguished on the basis of the pattern of immunostaining, at either $\mathrm{Pl}$ or $\mathrm{P} 8$, indicating that the $p c d$ mutation does not affect postnatal expression of nestin in the cerebellum.

As in the rat (Hockfield and McKay, 1985), in addition to Bergmann fibers that were already intensely immunopositive in the newborn mouse, but that are even clearer at P8 when characteristic palisades extending through the molecular and external granule cell layers were visible (Fig. 2A), cerebellar endothelial cells and astrocytic processes in the granule cell layer were labeled by the Rat-401 antibody. Diffuse but dense immunostaining could also be observed in white matter in both P1 and P8 mouse pups.

In cerebella of 2-4-month-old adult $p c d$ mice, Bergmann fibers, astrocytic processes, and white matter have lost the Rat401 antigen. Light staining remains visible, however, throughout the entire cortex, but most markedly in the atrophic molecular layer. In regions where this staining was most intense, cell bodies and a network of highly ramified and crenelated processes, corresponding to microglial cells, could be observed (Fig. $2 B$ ). Also, as in lesion-induced reactive gliosis in the rat (S. Hockficld, personal communication), some astrocytes in the adult $p c d$ cerebellum reexpressed the Rat-401 antigen. Figure $2 C$ shows the lesion made by the glass cannula used for implantation of the graft, the track of which is delineated by nestin-positive astrocytic processes. Bergmann fibers adjacent to the lesion remained negative, however.

\section{Detection of $\beta$-galactosidase in Bergmann fibers of pcd mice grafted with Krox-20/lacZ14 transgenic cerebellar primordia}

Host mice, with grafts either in the cerebellar parenchyma or between adjacent folia, were killed 1 or 2 months after grafting, when grafted Bergmann fibers had reached maturity and fully expressed the lac $Z$ reporter gene. The same results were obtained regardless of the location of the grafts.

Figure $1 D$ shows a large graft remnant within lobule VI, consisting of a lobular, trilayered mini-cerebellar structure with CaBP-positive $\mathrm{PC}$ dendrites in the molecular layer that is bordered by the immunopositive PC cell bodies. PCs that had migrated into the host molecular layer (ventral molecular layer of lobule VI, dorsal molecular layer of lobule VIII) are visible more peripherally (Fig. $1 D, E$ ). Expression of the lacZ gene in the graft remnant resembled that observed in the cerebellum of the transgenic mice. No $\beta$-galactosidase activity could be detected, however, in the molecular layer of the $p c d$ host containing grafted PCs that have left the implant (Fig. $1 D, E$ ).

Golgi epithelial cells and their Bergmann fibers in the graft remnant, when they had matured, expressed the transgene with the same pattern as in P22 transgenic animals. These cells re- mained in the graft and did not migrate into the host molecular layer along with the PCs.

\section{Spatiotemporal pattern of nestin (Rat-401 antigen) expression in Bergmann fibers of pcd mice grafted with isogenic cerebellar primordia}

During tangential migration ( $D A G 5$ ). In the animal analyzed, a small transplant was located partially within and partially outside of the cerebellum. In two of the folia adjacent to the intracerebellar portion of the graft, a few migrating PCs (horizontally oriented, bipolar, CaBP-positive cells) had invaded the surface of the host molecular layer. Immunostaining of the same sections with the Rat-401 antibody detected the presence of the antigen only in microglial cells which were lightly stained. No Bergmann fibers were labeled. The graft remnant was stained intensely by the Rat-401 antibody (data not shown).

During radial migration ( $D A G 7$ ). Graft remnants, frequently present in the interfolial space between host molecular layers into which grafted PCs had migrated, contained only a few immature PCs (CaBP-positive neurons, almost devoid of processes) (Figs. $3 C, 4 A$ ), but still exhibited diffuse and intense Rat401 staining (Figs. $3 B, D ; 4 B$ ).

Migrating PCs (radially oriented, bipolar, CaBP-positive cells with short ascending and long descending processes, the latter frequently branched into two thinner processes) were visible at various depths and densitics in the host molccular layer (Fig. $3 A, C$ ), which now expressed Rat-401 immunoreactivity. The antigen was expressed, however, only in areas with radially $\mathrm{mi}$ grating PCs (Fig. 3B,D). In most instances, the density of migrating $\mathrm{PCs}$ was directly related to the intensity of Rat-401 staining of Bergmann fibers (Fig. 3). In some cases, however, the presence of a few migrating PCs had sufficed to induce intense antigen expression in the corresponding fibers. Narrow bands of immunoreactive fibers free of migrating PCs could also be observed (Fig. $3 A, B$ ). An extreme case of disparity between $\mathrm{PC}$ density and nestin expression is shown in Figure $4, A$ and $B$. In spite of these exceptions, the spatial correlation between reexpression of the Rat-401 antigen in host Bergmann fibers and the radial migration of grafted embryonic PCs is clear.

Postmigration ( $D A G$ 13). The PCs had finished their migration and were developing their mature dendritic trees. The CaBPpositive cells were either stellate or had multiple primary dendrites (Fig. $4 C$ ), characteristic of the transition from the "phase of stellate cells with disoriented dendrons" to the "phase of orientation and fiattening of dendrites" (Ramon y Cajal, 1911).

Bergmann fibers in the host no longer express the Rat-401 antigen. Only lightly stained microglial cells could be detected in the molecular layer (Fig. 4D).

\section{Discussion}

When embryonic PCs migrate from an implant into the molecular layer of adult PC-deficient hosts, the final stage of migration is guided by Bergmann glial fibers (Sotelo and AlvaradoMallart, 1987b; Sotelo et al., 1990). The question asked in the

within the host molecular layer, and the reexpression of Rat-401 antigen by host Bergmann fibers. The arrowhead points to a small region of host molecular layer with reexpression of Rat-401 staining but without apparent migrating PCs. $C$ and $D$, Higher magnification of another transplanted cerebellum. The graft remnant $(G R)$ is almost devoid of CaBP-positive neurons (arrows) but is intensively stained by Rat-401 antibody (star). Numerous CaBP-positive neurons migrate radially in the host molecular layer, a region where host Bergmann fibers express Rat-401 antigenicity. Note, in the adjacent folium, that the molecular layer $(M L)$ is devoid of migrating PCs and of Rat-401-immunolabeled Bergmann fibers. Magnification: $A$ and $B, 75 \times ; C$ and $D, 270 \times$. 

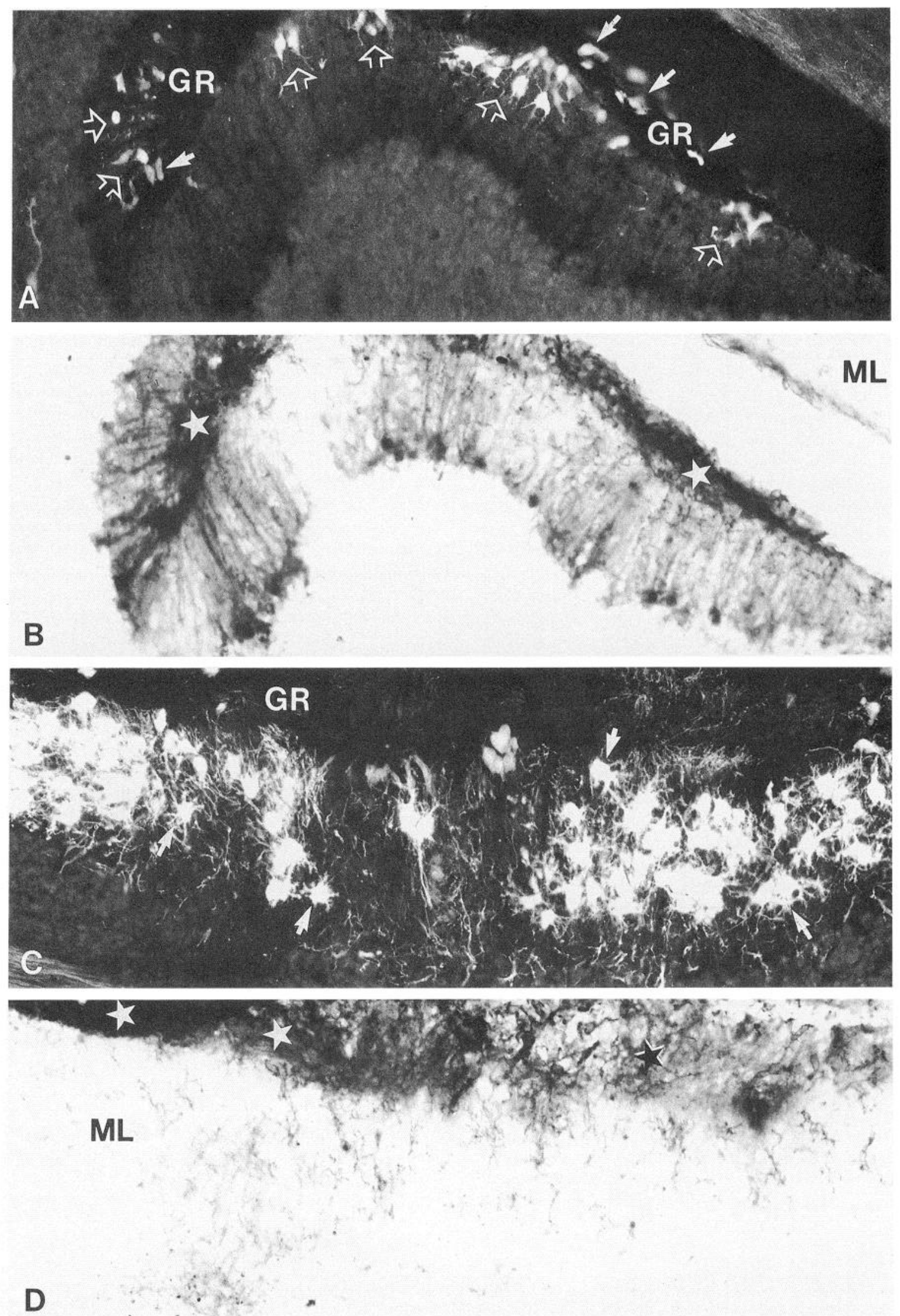

Figure 4. Rat-401 immunostaining of host Bergmann fibers at 7 DAG $(A, B)$ and its extinction at 13 DAG $(C, D)$ : sagittally cut cerebella, double labeled with mAb Rat-401 and anti-CaBP antisera. $A$ and $B$, At 7 DAG, the graft remnant $(G R)$ is intensely immunostained by Rat-401 (stars) and contains a few CaBP-positive neurons (solid arrows). The host molecular layer adjacent to the graft remnant contains Rat-401-immunoreactive 
present study was whether these were adult fibers from the host, and if so, how did they accomplish this task, or whether embryonic glial cells have also comigrated and thus express the appropriate molecular signals to facilitate $\mathrm{PC}$ invasion.

\section{Radial glial and Bergmann fiber as neuronal migratory axes}

The concept of glial guidance, derived from the observation of a tight association between migrating granule cells and Bergmann fibers in the developing molecular layer of the cerebellum (Rakic, 1971), underlies a commonly used mechanism for the positioning of young postmitotic neurons in developing brain. PC migration, during development, is guided, if at all, by radial glia not Bergmann fibers, which appear too late in fetal development and do not span the necessary distance from the ventricular neuroepithelium to the nascent PC plate (Misson et al., 1988). Bergmann fibers do, however, guide the migration of granule cells postnatally (Rakic, 1971).

\section{Host and not donor Bergmann fibers subserve migration to grafted PCs}

Bergmann fibers are specialized astrocytes (Ramon y Cajal, 1911), which can develop from radial glial cells (Rakic, 1984), and may therefore share the phenotypic traits that allow both to guide the migration of a given type of neuron. Previous studies have shown that implanted glial cells (oligodendrocytes and astrocytes) are indeed able to migrate into host brains. Although most of the experiments involved grafts into newborn hosts (Gumpel et al., 1983; Jacque et al., 1986, 1992; Suard et al., 1989; Zhou et al., 1990), migration of grafted astrocytes has also been observed in adult brain (Lindsay and Raisman, 1984; Goldberg and Bernstein, 1988). In grafting experiments like those presented here, vimentin-positive astrocytic processes that straddle the graft and the $p c d$ host molecular layer have been observed by DAG 6 (Sotelo et al., 1990).

The present study, in which Bergmann fibers developing in an embryonic implant would specifically express the reporter lacZ gene (M. Frain, P. Charnay, R. Werhle, and C. Sotelo, unpublished observations), demonstrated that $\beta$-galactosidasepositive fibers remain in the graft. First of all, no blue-stained fibers were observed in the host molecular layer. Second, the intensity of staining in the graft remnants suggests that there has been no loss of lacZ-expressing cells from the graft. Nevertheless, one cannot exclude that there has been proliferation of $\beta$-galactosidase-positive cells in the graft or after migration, and that these cells in their new environment, if they acquire the Bergmann phenotype, no longer express the transgene. Previous studies with tritiated thymidine have revealed, however, that the only autoradiographically labelled nuclei in the transplanted $p c d$ cerebellum belong to grafted PCs (Sotelo et al., 1990). Therefore, it is highly probable that adult host Bergmann fibers guide the migration of grafted PCs.

This "abnormal" migration strongly suggests that a common mechanism must exist in cerebellum for guiding neurons to their appropriate position, regardless of the type of neuron or the glial cell involved. This may be an illustration in vivo of the "passive generic" guidance evoked by Hatten (1990) to explain the in vitro migration of hippocampal or cerebellar neurons on glia from the heterologous region. Glial cells that present migratory axes, whatever their age, differentiated state, or region of origin, must therefore be capable of expressing the molecules necessary for the neuron/glial interaction to take place.

\section{Transient Rat-401 expression in glial axes subserving neuronal migration}

What are the molecules involved in the neuron/glial interaction? A large number of studies have attempted to elucidate the molecular mechanisms of glial guidance (Lindner et al., 1983, 1986; Persohn and Schachner, 1987). Multiple receptor systems are thought to be involved (Tomaselli et al., 1988; Hatten, 1990); for example, surface adhesion molecules on neurons and glia (Lindner et al., 1983) and cytoskeleton-related receptors such as the integrins (Hynes, 1987). The present study suggests that one of these molecules may be the intermediate filament nestin (Lendahl et al., 1990); recognized by mAb Rat-401, that was expressed only in those Bergmann fibers on which grafted PCs were migrating, and in the same time window that has been reported for radial migration of these grafted neurons (Sotelo et al., 1990).

The regulatory factors governing nestin expression have not been determined, but its timing and localization have been described. Present in almost all cells in the proliferative zone of the rat neural tube before neurons differentiate, it has been considered to be a marker of the immediate precursor to neurons (Lendahl et al., 1990). Nevertheless, nestin is also present in glial cells. Hence, coexpression of the Rat-401 antigen and glial fibrillary acidic protein has been observed in primary cultures, presumably in glial cells (Frederiksen and McKay, 1988). The anti-nestin antibody also stains radial glial cells during development (Hockfield and McKay, 1985), which may mean that these cells not only play an important role in neuronal migration, but may also be neuronal precursors (Lendahl et al., 1990). In addition to its ostensible role in neuronal differentiation and guidance, expression of low levels of nestin in microglia and reexpression in reactive astrocytes suggests that it has other functions as well. The nature of these functions is unknown.

In the developing rat cerebellum, the nestin gene is expressed from E19 to P9 with a peak at P5 (Lendahl et al., 1990). This does not coincide with proliferation of neurons from the ventricular epithelium (E12-E16). Neurons in the external granule layer are born between P1 and P19 (Altman, 1982), but studies in rat (Hockfield and McKay, 1985) and mouse (present results) suggest that none or only a few precursor cells in this secondary neuroepithelium may express the nestin protein, and ultrastructural analysis would be needed to determine the nature of these cells. The transient expression of the nestin gene (Lendahl et al., 1990) and protein (Hockfield and McKay, 1985; present results)

\footnotetext{
Bergmann fibers. In this exceptional situation, this region of molecular layer has very few grafted PCs (open arrows), in comparison to the intensity and extent of Rat-401-positive Bergmann fibers. $M L$ marks the molecular layer of the adjacent folium, free of migrating PCs and of Rat-401stained Bergmann fibers. $C$ and $D$, At 13 DAG the graft remnant $(G R)$ is always immunostained by the mAb Rat-401 (stars), but the adjacent host molecular layer $(M L)$ has missed its Rat-401-positive Bergmann fibers (only the light microglial staining is visible). The disappearance of Bergmann fibers' immunoreactivity coincides with the arrest of grafted PC migration. These neurons are now dispersed throughout the host molecular layer, and are building up their dendritic arbors (most of these PCs are in the phase of "stellate cells with disoriented dendrons"; arrows). Magnification, $220 \times$ for $A-D$.
} 
is, however, correlated with the appearance of Golgi epithelial cells and their Bergmann fibers (Miale and Sidman, 1961; Shiga et al., 1983). Nestin, in postnatal cerebellum, may therefore be a marker, not of neuronal proliferation, but of Bergmann fibers during granule cell migration.

\section{Migration of grafted PCs and transient reexpression of Rat-401 in host Bergmann fibers}

The present study suggests that nestin is also a marker of Bergmann fibers guiding the ectopic and heterochronic migration of grafted PCs in the adult host. Indeed, the expression of nestin in these adult glial fibers seems to be regulated by the presence of the grafted PCs, given the spatiotemporal correlation between radial migration and antigen expression reported here. This is not the only example of a PC-related change in Bergmann fiber phenotype. Late degeneration of PCs in the cerebella of nervous, pcd, and lurcher mutant mice (Fisher, 1984), and in murine chimeras (Fisher and Mullen, 1988), has been reported to be temporally correlated with loss of a specific adult isozyme of $s n$-glycerol-3-phosphate dehydrogenase (GPDH) that is normally present in the fibers. The mechanism underlying this phenomenon would appear to be different, however, from the induction of nestin expression observed in the present study. Whereas GPDH expression seems to require sustained interaction between the neurons and the glia, the presence of normal PCs in the adult cerebellum and the nodulus of the $p c d$ cerebellum does not prevent the developmentally regulated disappearance of the Rat-401 antigen from Bergmann fibers, nor does the proximity of grafted PCs, at least at DAG 13, sustain reexpression of the antigen beyond the period of radial migration. It sccms probable that a surface antigen and/or a soluble molecule of limited diffusion, expressed by PC only during migration, regulates the level and duration of nestin expression in the Bergmann fibers, but the nature of the signaling molecules remains to be determined.

In conclusion, this study has shown that adult glial cells can change their phenotypic expression in the presence of embryonic neurons, recapitulaling transient phenotypes associated with specific stages of normal development. In the sense that grafted embryonic PCs seem to regulate gene expression in neural cells of the adult host, we have termed this new type of glial transformation "adaptive rejuvenation." These changes generate, transiently, a microenvironment permitting radial migration of the PCs, the necessary precondition for their synaptic integration and the restoration of normal circuitry in the cerebellar cortex of pcd mice (Sotelo and Alvarado-Mallart, 1987b).

\section{References}

Altman J (1982) Morphological development of the rat cerebellum and some of its mechanisms. In: The cerebellum: new vistas (Palay SL, Chan-Palay V, eds), pp 8-49. Heidelberg: Springer.

Caddy KWT, Biscoe TJ (1979) Structural and quantitative studies on normal C3H and lurcher mutant mouse. Philos Trans R Soc Lond [Biol] 287:167-201.

Chavrier $\mathbf{P}$, Janssen-'Timmen U, Mattei $M G$, Zerial M, Bravo R, Charnay $P$ (1989) Structure, chromosome location and expression of the mouse zinc finger gene Krox-20: multiple gene products and coregulation with proto-oncogene c-fos. Mol Cell Biol 9:787-797.

Dumesnil-Bousez N, Sotelo C (1992) Early development of the lurcher cerebellum: Purkinje cell alterations and impairment of synaptogenesis. J Neurocytol 21:506-529.

Dumesnil-Bousez N, Sotelo C (1993) Partial reconstruction of the adult lurcher cerebellar circuitry by neural grafting. Neuroscience 51: $1-21$.
Fisher M (1984) Neuronal influence on glial enzyme expression: evidence from mutant mouse cerebella. Proc Natl Acad Sci USA 81: 4414-4418.

Fisher M, Mullen RJ (1988) Neuronal influence on glial enzyme expression: evidence from chimeric mouse cerebellum. Neuron 1:151157.

Frederiksen K, McKay RDG (1988) Proliferation and differentiation of rat neuroepithelial precursor cells in vivo. J Neurosci 8:1144-1151.

Goldberg W, Bernstein J (1988) Fetal cortical astrocytes migrate from cortical homographs throughout the host brain and over the glia limitans. J Neurosci Res 20:38-45.

Gumpel M, Baumann N, Raoul M, Jacque C (1983) Survival and differentiation of oligodendrocytes from neuronal tissue transplanted into newborn mouse brain. Neurosci Lett 37:307-312.

Hatten ME (1990) Riding the glial monorail: a common mechanism for glial-guided neuronal migration in different regions of the developing mammalian brain. Trends Neurosci 13:179-184.

Hockfield S, McKay RDG (1985) Identification of major cell classes in the developing mammalian nervous system. J Neurosci 5:33103328 .

Hogan BLM, Costantini F, Lacy E (1986) Manipulating the mouse embryo. A laboratory manual. Cold Spring Harbor, NY: Cold Spring Harbor Laboratory.

Hynes KO (1987) Integrins: a family of cell surface receptors. Cell 48: $549-554$.

Jacque C, Suard I, Collins P, Raoul M (1986) Identification of astrocytes after intracerebral transplantation. Dev Neurosci 8:142-149.

Jacque C, Quinonero J, Collins PV, Villarroya H, Suard I (1992) Comparative migration and development of astroglial and oligodendroglial cell populations from a brain xenograft. J Neurosci 12:3098-3106.

Lendahl U, Zimmermann LB, McKay RDG (1990) CNS stem cells express a new class of intermediate filament protein. Cell 60:585595.

Lindner J, Rathjen FG, Schachner M (1983) L1 mono- and polyclonal antibodies modify cell migration in early postnatal mouse cerebellum. Nature 305:427-430.

Lindner J, Guenther J, Nick H, Zinser G, Antonicek H, Schachner M, Monard D (1986) Modulation of granule cell migration by a gliaderived protein. Proc Natl Acad Sci USA 83:4568-4571.

Lindsay R, Raisman G (1984) An autoradiographic study of neural development, vascularization and glial cell migration from hippocampal transplants labelled in intermediate explant culture. Neuroscience 12:513-530.

Miale IL, Sidman RL (1961) An autoradiographic analysis of histogenesis in the mouse cerebellum. Exp Neurol 4:277-296.

Misson JP, Edwards ME, Yamamoto M, Caviness VS Jr (1988) Identification of radial glial cells within the developing murine central nervous system: studies based upon a new histochemical marker. Dev Brain Res 44:95-108.

Mullen RJ, Eicher EM, Sidman RL (1976) Purkinje cell degeneration, a new neurological mutation in the mouse. Proc Natl Acad Sci USA 73:208-212.

Persohn E, Schachner M (1987) Immunoelectron microscopic localization of the neural cell adhesion molecules L1 and N-CAM during postnatal development of the mouse cerebellum. J Cell Biol 105:569576.

Rakic P (1971) Neuron-glia relationship during granule cell migration in developing cerebellar cortex. A Golgi and electron microscopic study in Macacus rhesus. J Comp Neurol 141:283-312.

Rakic P (1984) Emergence of neuronal and glial cell lineages in primate brain. In: Cellular and molecular biology of neural development (Black IB, ed), pp 29-50. New York: Plenum.

Ramon y Cajal S (1911) Histologie du système nerveux de l'homme et des vertébrés, Vol 2, pp 80-106. Paris: Maloine.

Sanes JR, Rubenstein JLR, Nicolas JF (1986) Use of a recombinant retrovirus to study postimplantation cell lineage in mouse embryos. EMBO J 5:3133-3142.

Shiga T, Ichikawa M, Hirata Y (1983) Spatial and temporal pattern of postnatal proliferation of Bergmann glial cells in rat cerebellum: an autoradiographic study. Anat Embryol (Berl) 167:203-211.

Sidman RL, Green MC. (1970) "Nervous" a new mutant with cerebellar disease. In: Les mutants pathologiques chez l'animal (Sabourdy M, ed), pp 69-79. Paris: Centre National de la Recherche Scientifique.

Sotelo C, Alvarado-Mallart RM (1986) Growth and diffcrentiation of cerebellar suspensions transplanted in the adult cerebellum of mice 
with heredo-degenerative ataxia. Proc Natl Acad Sci USA 83:11351139.

Sotelo C, Alvarado-Mallart RM (1987a) Reconstruction of the defective cerebellar circuitry in adult Purkinje cell degeneration mutant mice by Purkinje cell replacement through transplantation of solid embryonic implants. Neuroscience 20:1-22.

Sotelo C, Alvarado-Mallart RM (1987b) Embryonic and adult neurons interact to allow Purkinje cell replacement in mutant cerebellum. Nature 327:421-423.

Sotelo C, Alvarado-Mallart RM (1991) The reconstruction of cerebellar circuits. Trends Neurosci 14:350-355.

Sotelo C, Alvarado-Mallart RM (1992) Cerebellar grafting as a tool to analyze new aspects of cerebellar development and plasticity. In: The cerebellum revisited (Llinas R, Sotelo C, eds), pp 84-115. New York: Springer.

Sotelo C, Alvarado-Mallart RM, Gardette R, Crepel F (1990) Fate of grafted Purkinje cells in the cerebellum of the adult "Purkinje cell degeneration" mutant mousc. I. Devclopment of reciprocal graft-host interactions. J Comp Neurol 295:165-187.

Spencer R, Charman H, Emtage JS, Lawson DEM (1976) Production and properties of vitamin D-induced mRNA for chick calcium-binding protein. Eur J Biochem 71:399-409.

Sternberger LA, Hardy PH Jr, Cuculis JJ, Meyer HG (1970) The unlabeled antibody enzyme method of immunohistochemistry. Preparation and properties of soluble antigen-antibody complex (horseradish peroxidase-antiperoxidase) and its use in identification of spirochetes. J Histochem Cytochem 18:135-333.

Suard I, Collins P, Ignacio V, Jacque C (1989) Implantation of rabbit embryo brain fragments into newborn mice: integration and survival of xenogeneic astrocytes. J Neurosci Res 23:172-179.

Tomaselli JJ, Neugebauer KM, Bixby J, Lilien J, Reichardt LF (1988) Two receptor systems that mediate neuronal process outgrowth on astrocytic surfaces. Neuron 1:33-43.

Wassef M, Sotelo C, Cholley B, Brehier A, Thomasset M (1987) Cerebellar mutations affecting the postnatal survival of Purkinje cells in the mouse disclose a longitudinal pattern of differentially sensitive cells. Dev Biol 124:379-389.

Zhou HF, Lee LHC, Lund R (1990) Timing and patterns of astrocyte migration from xenogenic transplants of the cortex and corpus callosum. J Comp Neurol 292:320-330. 